\title{
Apnea stimulates the adaptive response to oxidative stress in elephant seal pups
}

\author{
José Pablo Vázquez-Medina1, ${ }^{1, *}$ Tania Zenteno-Savín², Michael S. Tift ${ }^{3}$, Henry Jay Forman ${ }^{1}$, \\ Daniel E. Crocker ${ }^{3}$ and Rudy M. Ortiz ${ }^{1}$ \\ ${ }^{1}$ School of Natural Sciences, University of California, Merced, Merced, CA 95343, USA, '2Planeación Ambiental y Conservación, \\ Centro de Investigaciones Biológicas del Noroeste, SC, La Paz, BCS, Mexico and ${ }^{3}$ Department of Biology, Sonoma State \\ University, Rohnert Park, CA 94928, USA \\ *Author for correspondence (jvazquez-medina@ucmerced.edu)
}

Accepted 4 October 2011

\begin{abstract}
SUMMARY
Extended breath-hold (apnea) bouts are routine during diving and sleeping in seals. These apneas result in oxygen store depletion and blood flow redistribution towards obligatory oxygen-dependent tissues, exposing seals to critical levels of ischemia and hypoxemia. The subsequent reperfusion/reoxygenation has the potential to increase oxidant production and thus oxidative stress. The contributions of extended apnea to oxidative stress in adapted mammals are not well defined. To address the hypothesis that apnea in seals is not associated with increased oxidative damage, blood samples were collected from northern elephant seal pups $(N=6)$ during eupnea, rest- and voluntary submersion-associated apneas, and post-apnea (recovery). Plasma 4-hydroxynonenal $(\mathrm{HNE})$, 8-isoprostanes $\left(8\right.$-isoPGF $\left.{ }_{2 \alpha}\right)$, nitrotyrosine $(\mathrm{NT})$, protein carbonyls, xanthine and hypoxanthine $(\mathrm{HX})$ levels, along with xanthine oxidase (XO) activity, were measured. Protein content of $\mathrm{XO}$, superoxide dismutase 1 (Cu,ZnSOD), catalase and myoglobin (Mb), as well as the nuclear content of hypoxia inducible factor $1 \alpha$ (HIF-1 $\alpha$ ) and NF-E2-related factor 2 (Nrf2), were measured in muscle biopsies collected before and after the breath-hold trials. HNE, 8-iso PGF $2 \alpha$, NT and protein carbonyl levels did not change among eupnea, apnea or recovery. XO activity and $\mathrm{HX}$ and xanthine concentrations were increased at the end of the apneas and during recovery. Muscle protein content of XO, CuZnSOD, catalase, Mb, HIF-1 $\alpha$ and Nrf2 increased 25-70\% after apnea. Results suggest that rather than inducing the damaging effects of hypoxemia and ischemia/reperfusion that have been reported in non-diving mammals, apnea in seals stimulates the oxidative stress and hypoxic hormetic responses, allowing these mammals to cope with the potentially detrimental effects associated with this condition.
\end{abstract}

Key words: antioxidant, apnea, elephant seal, hypoxemia, ischemia, reperfusion, oxidative stress.

\section{INTRODUCTION}

Seals are routinely exposed to breath-holding (apnea) bouts while diving and sleeping (Elsner and Gooden, 1983; Kooyman, 1989; Ridgway et al., 1975). Apnea in seals is characterized by a series cardiovascular adjustments (reduction in cardiac output, bradycardia, peripheral vasoconstriction) that allow seals to maximize the use of their oxygen stores but at the same time result in blood oxygen depletion and blood flow redistribution towards obligatory oxygendependent tissues, exposing seals to critical levels of ischemia and hypoxemia (Castellini et al., 1994; Elsner, 1999; Kooyman and Ponganis, 1998; Stockard et al., 2007). At the end of an apnea bout, an increase in cardiac output and ventilation restores blood flow to tissues and blood oxygen content, presenting seals with potential increases in oxidant production and oxidative stress (Elsner et al., 1998; Zenteno-Savín et al., 2002).

Blood reoxygenation after hypoxemia and ischemia/reperfusion are conditions that, in terrestrial mammals, increase oxidant production and oxidative damage (McCord, 1985). During ischemia and hypoxemia, ATP degradation results in the accumulation of the purine nucleotides, xanthine and hypoxanthine (HX), and in the proteolytic conversion of xanthine dehydrogenase (XDH) to xanthine oxidase (XO). During reperfusion/reoxygenation, $\mathrm{XO}$ reduces xanthine and $\mathrm{HX}$, generating superoxide radical $\left(\mathrm{O}_{2}{ }^{-}\right)$and hydrogen peroxide $\left(\mathrm{H}_{2} \mathrm{O}_{2}\right)$ (Parks et al., 1983). Despite routine and chronic exposure to cyclic bouts of apnea-induced hypoxemia and ischemia/reperfusion, seals do not exhibit higher levels of oxidative damage (i.e. lipid peroxidation and protein carbonyls) in their tissues or red blood cells (RBCs) in comparison with terrestrial mammals (Vázquez-Medina et al., 2007; Wilhelm Filho et al., 2002; ZentenoSavín et al., 2002). Interestingly, seal tissues do accumulate HX after ex vivo exposure to ischemia (Elsner et al., 1998). Moreover, basal capacity to produce $\mathrm{O}_{2}{ }^{-}$is higher in tissues of seals than in tissues of non-diving mammals and $\mathrm{O}_{2}{ }^{-}$production, but not oxidative damage, is higher in seal than in terrestrial mammal tissues when exposed in vitro to an oxidant-generating system (xanthine + XO) (Zenteno-Savín et al., 2002). The latter suggests that seals, as well as other diving vertebrates (Furtado-Filho et al., 2007; Valdivia et al., 2007; Zenteno-Savín et al., 2010), are constantly exposed to apnea-induced oxidant production, but possess mechanisms to avoid oxidative damage. These mechanisms, however, are not well defined in mammals adapted to tolerate repetitive and routine bouts of apnea.

An enhanced antioxidant capacity likely contributes to the seal's tolerance to apnea-induced hypoxemia and ischemia/reperfusion (Hermes-Lima and Zenteno-Savín, 2002; Zenteno-Savín et al., 2002). Plasma, tissues and RBCs of seals possess higher basal activities of several antioxidant enzymes and higher glutathione (GSH) levels than those of terrestrial mammals (Murphy and Hochachka, 1981; Vázquez-Medina et al., 2006; Vázquez-Medina et al., 2007; Wilhelm Filho et al., 2002). Furthermore, hypoxia- 
inducible factor 1 (HIF-1), a key transcriptional regulator of the adaptive response to hypoxia, and NF-E2-related factor 2 (Nrf2), which controls the adaptive response to oxidative stress by upregulating antioxidant genes in response to increased oxidant production, have also been implicated in seal's protection against apnea-induced hypoxemia and ischemia/reperfusion (Johnson et al., 2004; Johnson et al., 2005; Vázquez-Medina et al., 2011b). No in vivo studies, however, have been conducted to elucidate the cellular and molecular responses that protect seals against apnea-induced hypoxemia and ischemia/reperfusion. The available data on the effects of submersion on antioxidant responses in seals are also scant, with results showing that blood GSH content in Weddell seals decreases during forced submersions and increases above presubmersion levels during recovery (Murphy and Hochachka, 1981).

In the present study, plasma levels of a suite of markers of oxidative damage, along with plasma XO activity and plasma concentrations of xanthine and HX, were measured in seals before, during and after rest- and voluntary submersion-associated apneas to assess the impact of apnea on oxidant mechanisms. Muscle protein levels of catalase, HIF-1 $\alpha$, myoglobin (Mb), Nrf2, superoxide dismutase 1 (Cu,ZnSOD) and $\mathrm{XO}$, along with muscle levels of oxidative damage, were also measured before and after a series of repetitive apneas to further examine the cellular mechanisms that protect seals against apneainduced hypoxemia and ischemia/reperfusion. We hypothesize that: (1) apnea does not increase muscle or systemic oxidative damage in elephant seals and (2) HIF-1 $\alpha$ and Nrf2 nuclear content, antioxidant enzymes and $\mathrm{Mb}$ expression increase in the skeletal muscle of elephant seals after repetitive apneas.

\section{MATERIALS AND METHODS}

All work was realized under the National Marine Fisheries Service marine mammal permit no. 87-1743. All procedures were approved by the Institutional Animal Care and Use Committees of the University of California, Merced, and Sonoma State University.

\section{Animal handling}

Eleven-week-old ( 7 week post-weaned, $N=6$ ) northern elephant seal pups (Mirounga angustirostris Gill 1866) were captured without sedation by rolling them into a transport cage, one at a time, at Año Nuevo State Park (30 km north of Santa Cruz, CA) and transported to Sonoma State University (Ronhert Park, CA) where the rest- and voluntary submersion-associated apnea experiments were conducted. Upon arrival at the laboratory, animals were allowed to recover from the transport for $6 \mathrm{~h}$. Animals were then sedated with $1 \mathrm{mg} \mathrm{kg}^{-1}$ tiletamine hydrochloride and zolazepam hydrochloride (telazol; Fort Dodge Animal Health, Fort Dodge, IA, USA), administrated intramuscularly prior to venous catheterization. Immobilization was maintained with $100 \mathrm{mg}$ intravenous injections of ketamine (Fort Dodge Animal Health) as needed. Sedation with telazol and ketamine does not activate the hypothalamicpituitary-adrenal axis in elephant seals (Champagne, 2011). With the exception of a different catheter tube, the catheterization procedure was similar to that previously reported for elephant seal pups (Ortiz et al., 2002). Eupenic samples (matching blood and muscle biopsies) were collected at this time, when the animals had been continuously breathing for at least $2 \mathrm{~h}$. Animals were allowed to recover from the catheterization overnight before the beginning of the apnea trials.

\section{Rest- and voluntary-submersion-associated apneas}

Caged animals were allowed to sleep in a large quiet room for up to $6 \mathrm{~h}$. For the purposes of this paper, rest-associated apneas were characterized by breath-holds with eyes closed, occasional facial twitching and lack of body movements (Castellini et al., 1994; Ponganis et al., 2006; Stockard et al., 2007). Following the restassociated apnea trials, animals were then transferred to a shallow water tank and allowed to submerge freely for another $6 \mathrm{~h}$. For the rest- and voluntary submersion-associated apnea studies, blood samples were collected at 1, 3, 7 and 9 min during breath-holds and at 1,3 and $5 \mathrm{~min}$ after the bouts (recovery). Venous oxygen partial pressure $\left(P_{\mathrm{O}_{2}}\right)$ was measured using a blood gas analyzer (Rapidlab 845, Bayer Diagnostic Division, Milan, Italy) to corroborate blood oxygen depletion during breath-holds (Stockard et al., 2007).

\section{Sample collection}

Blood samples were collected from the extradural spinal vein into pre-chilled EDTA-treated collection tubes containing $10 \mu \mathrm{ml}^{-1}$ protease inhibitor cocktail and $0.005 \%$ butylated hydroxytoluene (Sigma-Aldrich, St Louis, MO, USA). Samples were centrifuged for $15 \mathrm{~min}$ at $3000 \mathrm{~g}$ at $4^{\circ} \mathrm{C}$. Plasma was aliquoted into cryo-vials, frozen by immersion in liquid nitrogen and stored at $-80^{\circ} \mathrm{C}$. Muscle biopsies (ca. $10 \mathrm{mg}$ ) were collected during catheterization (eupnea) and immediately after the end of the submersion experiments (postapnea) using sterile $14 \mathrm{G} \times 15 \mathrm{~cm}$ Tru-Cut biopsy needles (Cardinal Health, McGaw Park, IL, USA). Samples were snap-frozen in liquid nitrogen and stored at $-80^{\circ} \mathrm{C}$.

\section{Plasma measurements}

Plasma levels of 8-isoprostanes (8-isoPGF $2 \alpha$ ) were measured using a competitive EIA assay kit (Cayman Chemical, Ann Arbor, MI, USA). Samples were extracted using ethanol, 30\% acetic acid and C-18 solid phase extraction cartridges. Plasma and muscle levels of nitrotyrosine (NT) and 4-hydroxynonenal (HNE), as well as plasma carbonyls, were also measured using commercially available ELISA kits (Cell BioLabs, San Diego, CA, USA) (Vázquez-Medina et al., 2010). Plasma XO activity and xanthine and HX concentrations were measured using an Amplex ${ }^{\circledR}$ Red assay kit (Molecular Probes, Eugene, OR, USA).

\section{Western blot}

Nuclear and cytosolic protein fractions were prepared from frozen tissue samples using the NE-PER nuclear and cytoplasmic extraction kit (Pierce, Rockford, IL, USA). Total protein content in both fractions was measured using the Bio-Rad Bradford protein assay (Bio-Rad Laboratories, Hercules, CA, USA). Twenty micrograms of cytosolic or $10 \mu \mathrm{g}$ of nuclear protein were mixed with Laemmli sample buffer, boiled and resolved in $4-15 \%$ Tris$\mathrm{HCl}$ gradient gels. Proteins were electroblotted for $25 \mathrm{~min}$ at $25 \mathrm{~V}$ using a Bio-Rad Trans Blot SD semi-dry cell or overnight at $34 \mathrm{~V}$ using the Bio-Rad Mini Protean transfer apparatus (for XO analyses) onto $0.45 \mu \mathrm{m}$ nitrocellulose membranes. Membranes were blocked for $1 \mathrm{~h}$ at room temperature and incubated overnight with primary antibodies against $\mathrm{Cu}, \mathrm{Zn} \mathrm{SOD}$ (Assay Designs, Ann Arbor, MI, USA), Mb (Abcam, Cambridge, MA, USA), catalase, HIF-1 $\alpha$, Nrf2 or XO (Santa Cruz Biotechnology, Santa Cruz, CA, USA), diluted 1:100 to 1:4000. Membranes were washed, incubated with horseradish-peroxidase-conjugated secondary antibodies (Santa Cruz Biotechnology), diluted 1:5000, re-washed and developed with the Immun-Star Western C kit (Bio-Rad Laboratories). Blots were visualized using a Chemi-Doc XRS system (Bio-Rad Laboratories) and quantified by using Bio-Rad's Quantity One software. Percent change from eupnea was calculated after band densities were normalized against actin (cytolosic proteins) or lamin (transcription factors). 


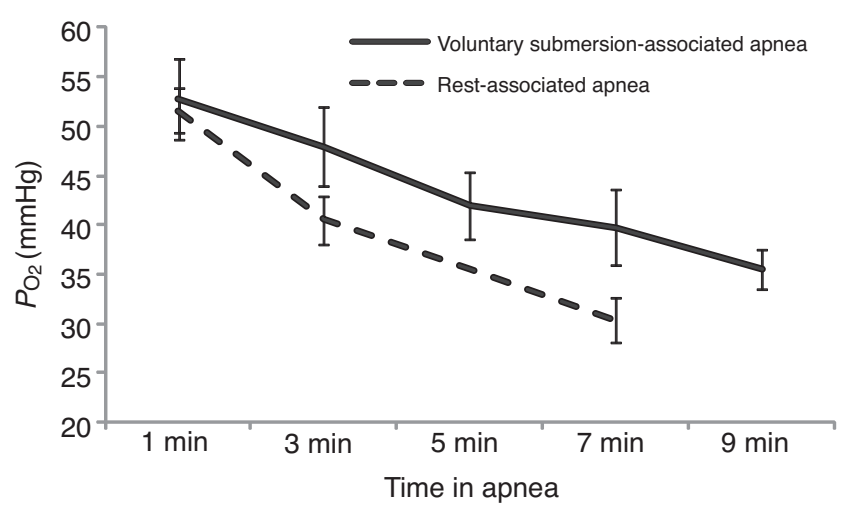

Fig. 1. Rest- and voluntary submersion-associated apneas promote blood oxygen depletion in elephant seal pups. Data shown are mean ( \pm s.e.m.) venous oxygen partial pressure $\left(P_{\mathrm{O}_{2}}\right)$ values $(\mathrm{mmHg})$ during rest- and voluntary submersion-associated apneas.

\section{Statistics}

Results from different time points were analyzed using general linear mixed models with individual seal as a random effect subject term. Means of eupnea and post-apnea muscle protein measurements were compared using paired $t$-tests. Means $( \pm$ s.e.m.) were considered significantly different at $P<0.05$. Statistical analyses were performed with the SYSTAT ${ }^{\odot} 11.0$ software (SPSS, Richmond, CA, USA).

\section{RESULTS

$$
\mathrm{PO}_{2}
$$

Venous $P_{\mathrm{O}_{2}}$ was measured during rest- and voluntary submersionassociated apneas to corroborate blood oxygen depletion during breath-holds. Venous $P_{\mathrm{O}_{2}}$ decreased $(P<0.05)$ from $51 \pm 2 \mathrm{mmHg}$ at
$1 \mathrm{~min}$ to $30 \pm 2 \mathrm{mmHg}$ at $7 \mathrm{~min}$ during rest-associated apneas and from $52 \pm 4 \mathrm{mmHg}$ at $1 \mathrm{~min}$ to $35 \pm 1 \mathrm{mmHg}$ at $9 \mathrm{~min}$ during voluntary submersion-associated apneas (Fig. 1).

\section{Purine metabolism}

Plasma content of xanthine and HX was measured before, during and after rest- and voluntary submersion-associated apneas to test whether apnea increases the circulating content of these ATP degradation products. HX content was higher $(P<0.05)$ during the recovery period $\left(190 \pm 20 \mathrm{mmoll}^{-1}\right)$ than at the end $\left(60 \pm 7 \mathrm{mmoll}^{-1}\right.$ at $\left.7 \mathrm{~min}\right)$ of the restassociated apneas (Fig. 2A). HX circulating concentration was also higher $(P<0.05)$ at the end $(5$ and $7 \mathrm{~min})$ than at the beginning ( 1 and $3 \mathrm{~min})$ of the voluntary submersions $\left(170 \pm 20\right.$ and $150 \pm 20 \mathrm{mmoll}^{-1}$ vs $60 \pm 20$ and $60 \pm 7 \mathrm{mmoll}^{-1}$, respectively) and returned to eupnea levels $\left(120 \pm 10 \mathrm{mmoll}^{-1}\right)$ during recovery $\left(110 \pm 10 \mathrm{mmoll}^{-1}\right.$; Fig. 2A). Xanthine circulating content was higher $(P<0.05)$ during the recovery period $\left(500 \pm 50 \mathrm{mmoll}^{-1}\right)$ than at the end of the rest-associated apneas $\left(230 \pm 40 \mathrm{mmoll}^{-1}\right.$ at $5 \mathrm{~min}$ and $260 \pm 30 \mathrm{mmoll}^{-1}$ at $\left.7 \mathrm{~min}\right)$. Plasma content of xanthine also decreased at the beginning of the voluntary submersions $\left(120 \pm 40 \mathrm{mmoll}^{-1}\right)$ and gradually increased until it reached eupnea levels $\left(340 \pm 50 \mathrm{mmoll}^{-1}\right)$ at $5 \mathrm{~min}\left(380 \pm 70 \mathrm{mmoll}^{-1}\right.$; $P<0.05$; Fig. 2B).

Plasma XO activity and muscle protein expression was measured to test whether this enzyme, which is responsible for $\mathrm{O}_{2}{ }^{-}$and $\mathrm{H}_{2} \mathrm{O}_{2}$ production upon reperfusion, increases in response to apnea. Plasma $\mathrm{XO}$ activity did not change during or after rest-associated apneas but was decreased $(P<0.01)$ during the beginning of the voluntary submersions $\left(0.5 \pm 0.06 \mathrm{mU} \mathrm{ml}^{-1}\right.$ at $1 \mathrm{~min}$ and $0.7 \pm 0.1 \mathrm{mU} \mathrm{ml}^{-1}$ at $3 \mathrm{~min})$ and increased gradually to eupnea levels $\left(1.5 \pm 0.1 \mathrm{mU} \mathrm{ml}^{-1}\right)$ at the end of the submersions $\left(1.4 \pm 0.1 \mathrm{mU} \mathrm{m}^{-1}\right.$ at $7 \mathrm{~min}$ and $1.6 \pm 0.3 \mathrm{mU} \mathrm{ml}^{-1}$ at $\left.9 \mathrm{~min}\right)$ and during recovery $\left(1.4 \pm 0.1 \mathrm{mU} \mathrm{ml}^{-1}\right.$; Fig. 2C). Mean muscle XO protein content increased by $25 \%$ after
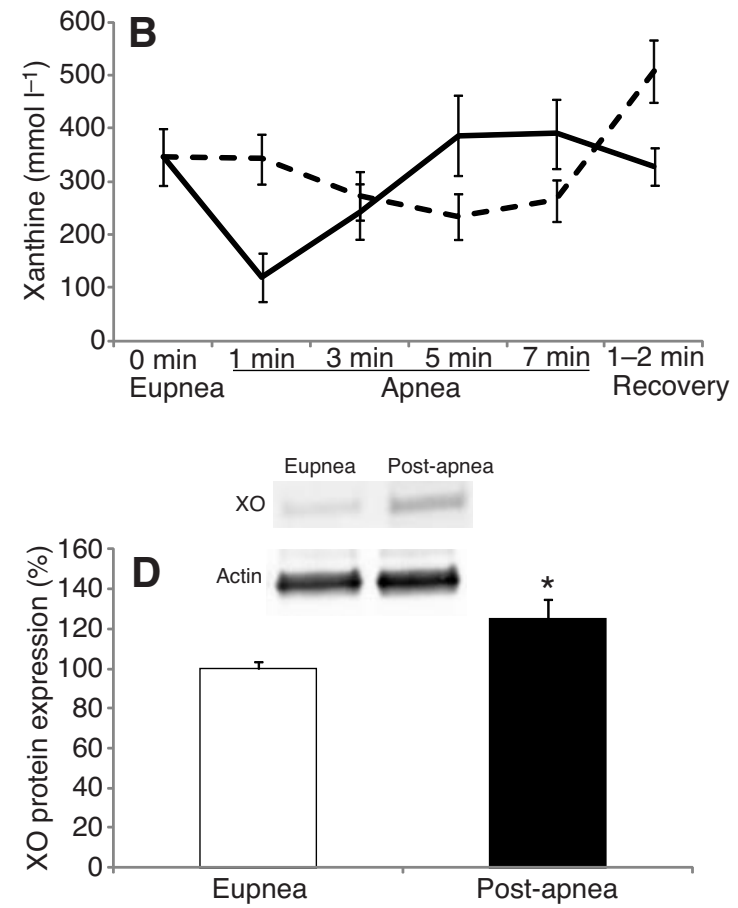

Fig. 2. Rest- and voluntary submersion-associated apneas increase hypoxanthine, xanthine and xanthine oxidase (XO) in elephant seal pups. Mean $( \pm$ S.e.m.) (A) plasma hypoxanthine concentration, (B) plasma xanthine concentration and (C) plasma XO activity before, during and after rest- and voluntary submersion-associated apneas, and (D) XO muscle protein expression before (eupnea) and after repetitive apneas. ${ }^{*}$ Significant $(P<0.05)$ difference from eupnea. 

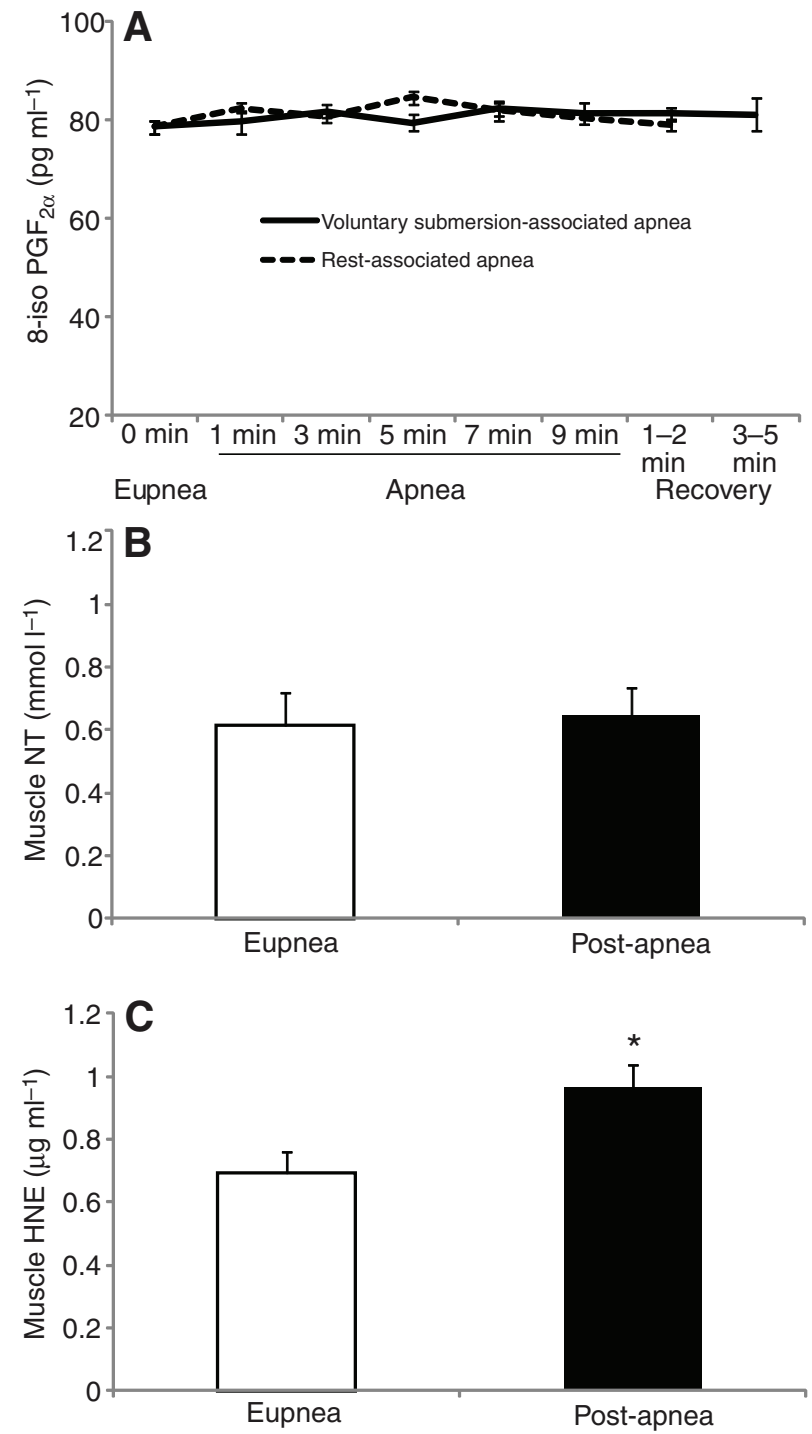

Fig. 3. Rest- and voluntary submersion-associated apneas do not induce oxidative damage in elephant seal pups. Mean ( \pm s.e.m.) (A) plasma concentration of 8-isoprostanes (8-isoPGF $\mathrm{P}_{2 \alpha}$ ) before, during and after restand voluntary submersion-associated apneas, and (B) muscle nitrotyrosine (NT) and (C) muscle 4-hydroxynonenal (HNE) concentration before (eupnea) and after repetitive apneas. ${ }^{*}$ Significant $(P<0.05)$ difference from eupnea.

apnea ( $P<0.05$; Fig. 2D). Taken together, these results suggest that rest- and voluntary submersion-associated apneas can potentially increase oxidant production in elephant seals through the activation of the $\mathrm{HX}-\mathrm{XO}$ pathway.

\section{Oxidative damage}

Plasma content of 8-isoPGF $2 \alpha$, HNE, NT and protein carbonyls, along with muscle levels of HNE and NT, were measured to test whether apnea increases oxidative damage in elephant seal pups. No differences in the plasma or the muscle levels of 8 -isoPGF $2 \alpha$, NT or protein carbonyls increased in response to rest- or voluntarysubmersion-associated apneas (Fig. 3A,B, Table 1). Only muscle HNE levels increased after repetitive apneas $(0.69 \pm 0.06$ vs $\left.0.96 \pm 0.07 \mu \mathrm{g} \mathrm{ml}^{-1}, P<0.05\right)$, suggesting that elephant seals do not suffer the detrimental effects of apnea-induced hypoxemia and ischemia/reperfusion that have been reported in terrestrial mammals.

\section{Muscle adaptive responses to apnea}

HIF-1 $\alpha$ and Nrf2 nuclear content, along with antioxidant enzymes $(\mathrm{Cu}, \mathrm{ZnSOD}$ and catalase) and $\mathrm{Mb}$ protein expression, were measured before and after repetitive apneas in muscle of northern elephant seal pups to test whether apnea upregulates these key proteins involved in the adaptive responses to hypoxia and oxidative stress. Muscle protein expression of $\mathrm{Cu}, \mathrm{Zn}$ SOD and catalase increased by 84 and 48\%, respectively ( $P<0.05$; Fig. 4A,B), whereas nuclear content of Nrf2 increased by $56 \%$ after apnea $(P<0.05$; Fig. 4C). The nuclear content of HIF- $1 \alpha$ and the protein expression of $\mathrm{Mb}$ also increased by 68 and $60 \%$, respectively $(P<0.05$; Fig. 5A,B), suggesting that apnea in seals activates the adaptive responses to hypoxia and oxidative stress, and that $\mathrm{HIF}-1 \alpha, \mathrm{Mb}$ and the antioxidant system play a role in the seal's tolerance against apnea-induced hypoxemia and ischemia/reperfusion.

\section{DISCUSSION}

Blood reoxygenation after hypoxemia and ischemia/reperfusion are critical conditions that, in terrestrial mammals, increase oxidant production and oxidative damage (Corral-Debrinski et al., 1991; McCord, 1985). Seals, however, naturally experience repetitive episodes of hypoxemia and ischemia/reperfusion associated with breath-holding during diving and sleeping (Elsner and Gooden, 1983; Kooyman, 1989; Ridgway et al., 1975). The present study demonstrates that, despite inducing hypoxemia and increasing xanthine, $\mathrm{HX}$ and $\mathrm{XO}$, apnea does not increase systemic oxidative damage or muscle protein nitration in elephant seals. Moreover, repetitive apneas stimulate protective responses against hypoxia and oxidative stress in the skeletal muscle of elephant seals.

The observed differences in the trends of circulating xanthine, $\mathrm{HX}$ and $\mathrm{XO}$ during rest-associated apneas and voluntary submersions may be due to differences in the degreee of the diving reponse observed during bouts of breath-holding with or without face immersion in the water. It has been consistently found that breath-holding with face immersion produces a more profound response (greater bradycardia and hypometabolism) than breathholding alone [for a complete review see Elsner (Elsner, 1999)]. Also, the decrease in circulating xanthine, $\mathrm{HX}$ and $\mathrm{XO}$ activity during the first minute of the voluntary submersions can be explained by the fact that submersion produces an immediate and profound splenic contraction without any further significant decrease in splenic volume after the second minute, resulting in higher hematocrit in venous ciruclation at the beginning of a submersion than during eupnea (Thornton et al., 2001).

Although routinely diving at sea $(>10 \mathrm{~min})$ results in extreme hypoxemia with near total blood oxygen depletion (arterial $P_{\mathrm{O}_{2}}$ values $=12 \mathrm{mmHg}$ ) (Meir et al., 2009), during rest-associated apneas, arterial $P_{\mathrm{O}_{2}}$ values in juvenile elephant seals decline exponentially, but only to approximately $18 \mathrm{mmHg}$ after $9 \mathrm{~min}$ (Stockard et al., 2007). Furthermore, the decline in muscle blood flow during restassociated apneas is gradual, suggesting that muscle ischemia during this condition is incomplete (Ponganis et al., 2008). These considerations, along with the lack of lactate accumulation, suggest that aerobic metabolism is maintained at low oxygen tensions during rest-associated apneas in elephant seals (Stockard et al., 2007), and partially explain the lack of systemic oxidative damage and muscle protein nitration, despite the observed increases in xanthine, HX and $\mathrm{XO}$ in response to rest- and voluntary submersion-associated apneas in elephant seal pups.

In contrast to extended ischemia, which promotes necrosis and triggers oxidant-mediated tissue damage upon reperfusion (Gottlieb et al., 1994), short ischemia/reperfusion intervals (preconditioning) 
Table 1. Mean ( \pm s.e.m.) plasma levels of oxidative damage markers before, during and after rest- and voluntary submersion-associated apnea in elephant seals

\begin{tabular}{|c|c|c|c|}
\hline & $\mathrm{HNE}\left(\mu \mathrm{g} \mathrm{ml}^{-1}\right)$ & NT $\left(\mathrm{nmoll} \mathrm{I}^{-1}\right)$ & Plasma carbonyls ( $\mathrm{nmol} \mathrm{mg}^{-1}$ protein) \\
\hline Eupnea & $2.2 \pm 0.08$ & $1.4 \pm 0.10$ & $0.37 \pm 0.02$ \\
\hline \multicolumn{4}{|l|}{ Rest-associated apnea } \\
\hline $1 \mathrm{~min}$ & $2.1 \pm 0.13$ & $1.5 \pm 0.07$ & $0.34 \pm 0.03$ \\
\hline Recovery (1-2 min) & $2.3 \pm 0.13$ & $1.4 \pm 0.07$ & $0.31 \pm 0.04$ \\
\hline \multicolumn{4}{|c|}{ Voluntary submersion-associated apnea } \\
\hline $1 \mathrm{~min}$ & $1.9 \pm 0.09$ & $1.4 \pm 0.05$ & $0.31 \pm 0.02$ \\
\hline
\end{tabular}

HNE, 4-hydroxynonenal; NT, nitrotyrosine.

attenuate reperfusion injury in myocardium and skeletal muscle (Mounsey et al., 1992; Murry et al., 1986; Pang et al., 1995). Low rates of oxidant generation during preconditioning are needed for the activation of protective pathways upon reperfusion (Baines et al., 1997). XO-derived $\mathrm{H}_{2} \mathrm{O}_{2}$ has been shown to increase superoxide dismutase (SOD) and GSH peroxidase mRNA, protein content and activity (Furuichi et al., 2005; Yuan et al., 2010; Zhu et al., 2011), as well as Nrf2 activation (Leonard et al., 2006; Umemura et al., 2008). The present study shows that repetitive exposure to breathholds in seals increases muscle XO protein expression along with an increase in Nrf2 nuclear content, SOD1 and catalase protein expression, without increasing muscle NT or circulating 8-isoPGF $2 \alpha$, HNE, NT or protein carbonyls, suggesting that XO-derived oxidant production does not induce oxidative damage, and rather contributes to the activation of the protective response against oxidative stress. The latter is consistent with the observed increases in plasma xanthine, HX and XO activity at the end of the apneas and during recovery, with the previously reported increases in HX after ex vivo exposure to ischemia in seal heart and kidney (Elsner et al., 1998), and with the increased content of muscle HNE after repetitive apneas, as HNE also contributes to the activation of the Nrf2mediated oxidative stress response (Siow et al., 2007; Tanito et al., 2007).

$\mathrm{Nrf} 2$ induces the transcription of genes involved in antioxidant defense such as SOD1 and catalase (Immenschuh and Baumgart-
Vogt, 2005; Jaiswal, 2004). This transcription factor is, under unaltered conditions, bound to its repressor protein Keap 1 in the cytosol, which targets its continuous proteosomal degradation (Itoh et al., 1997). Oxidants and electrophiles, such as $\mathrm{H}_{2} \mathrm{O}_{2}$ and $\mathrm{HNE}$, modify Keap1, promoting Nrf2 activation and nuclear accumulation (Bloom and Jaiswal, 2003; Kobayashi et al., 2004; Kobayashi et al., 2006; Zhang and Hannink, 2003). The observed increases in XO, HNE, Nrf2, SOD1 and catalase suggest that repetitive breathholds stimulate the hormetic response against oxidative stress in elephant seals, likely contributing to the upregulation of their antioxidant system and preparing them to cope with extended ischemia and hypoxemia while at sea.

While diving, elephant seals remain submerged $90 \%$ of the time (Le Boeuf et al., 1996). When resting on land, apnea bouts comprise up to $60 \%$ of their time sleeping (Blackwell and Le Boeuf, 1993). Although bouts of sleep apnea occur in all elephant seals regardless of age, weaned pups increase the number and duration of apneas at the end of their postweaning fast, when seals are learning to swim and dive, and just prior to initiating their diving lifestyle (Blackwell and Le Boeuf, 1993). Elephant seal pups also increase their antioxidant defenses at the end of their postweaning fast, suggesting that the activation of the antioxidant system in these mammals is an essential part of their developmental process and prepares them to dive, which is the next step in their life history (Vázquez-Medina et al., 2010; Vázquez-Medina et al., 2011c). The present results
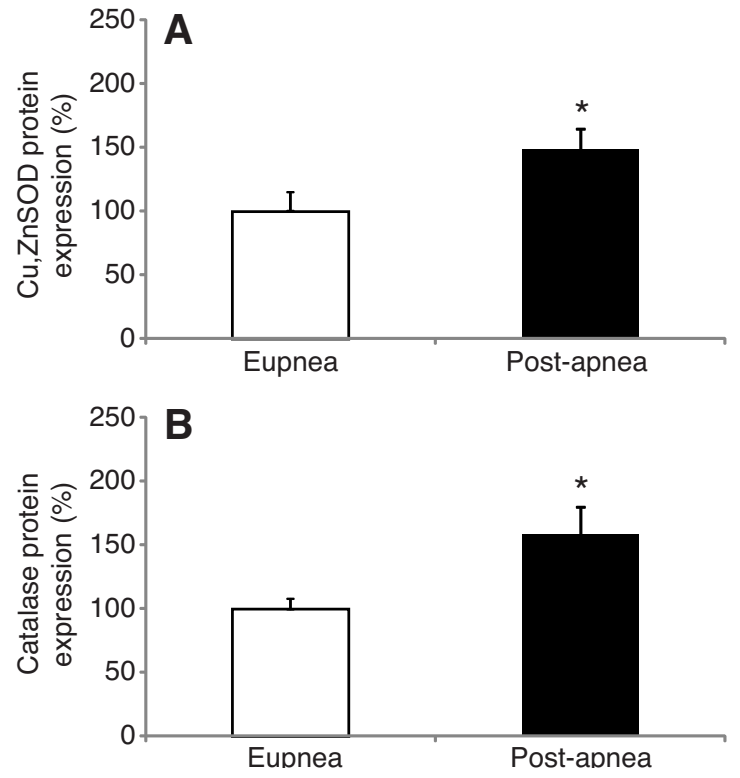
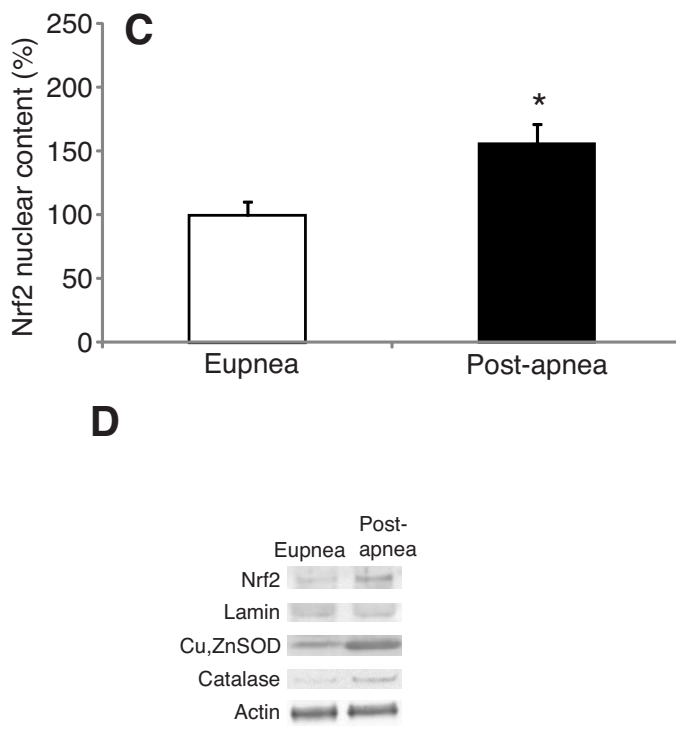

Fig. 4. Rest- and voluntary submersion-associated apneas activate the adaptive response to oxidative stress in elephant seal pups. Mean ( \pm s.e.m.) muscle protein expression of (A) superoxide dismutase 1 $(\mathrm{Cu}, \mathrm{ZnSOD})$ and $(\mathrm{B})$ catalase before (eupnea) and after repetitive apneas in elephant seal pups. (C) NF-E2-related factor 2 (Nrf2) nuclear content before (eupnea) and after repetitive apneas in elephant seal pups. (D) Representative western blot analyses of Nrf2, $\mathrm{Cu}, \mathrm{ZnSOD}$ and catalase protein expression in northern elephant seal pups. ${ }^{*}$ Significant $(P<0.05)$ difference from eupnea. 

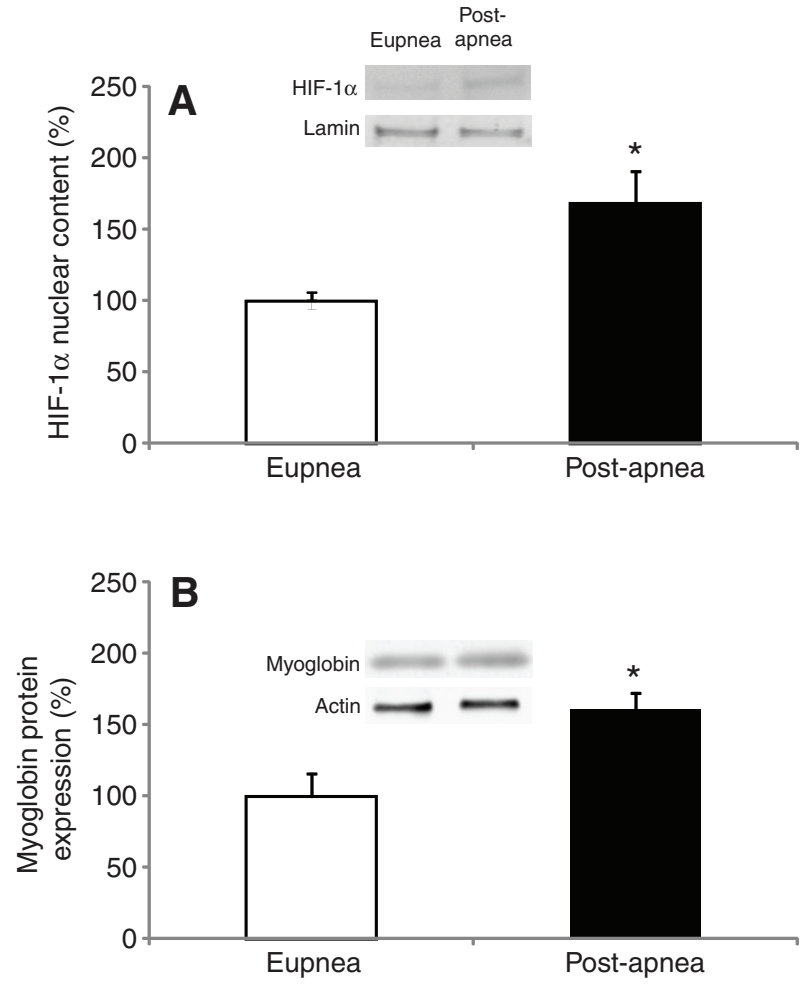

Fig. 5. Rest- and voluntary submersion-associated apneas activate the adaptive response to hypoxia in elephant seal pups. Mean ( \pm s.e.m.) (A) nuclear content of hypoxia inducible factor $1 \alpha$ (HIF-1 $\alpha$ ) and (B) protein expression of myoglobin (Mb) in skeletal muscle before (eupnea) and after repetitive apneas. *Significant $(P<0.05)$ difference from eupnea.

suggest that, because apnea stimulates the adaptive response to oxidative stress, and the number and duration of apneas increase with development in elephant seal pups, apnea is essential to prime the seal's antioxidant mechanisms that allow them to cope with the subsequent diving-induced hypoxemia and ischemia/reperfusion/ reoxygenation while at sea.

Maturation-related increases in antioxidant capacity have also been documented in the deep-diving hooded seal (Vázquez-Medina et al., 2011a; Vázquez-Medina et al., 2011b), in which oxygen stores (hemoglobin and $\mathrm{Mb}$ content), acid buffering capacity, and aerobic and anaerobic enzyme activities also increase with maturation in the skeletal muscle (Burns et al., 2007; Burns et al., 2010; Lestyk et al., 2009). In the present study, repetitive apneas increased $\mathrm{Mb}$ expression and HIF-1 $\alpha$ nuclear content in the skeletal muscle of elephant seals. Under normoxia, HIF-1 $\alpha$ is hydroxylated at proline and asparagine residues, which allows its interaction with the von Hippel-Lindau protein, causing HIF-1 $\alpha$ ubiquitination and its subsequent proteosomal degradation (Ivan et al., 2001). Under hypoxia, hydroxylation of HIF- $1 \alpha$ is prevented, causing its interaction with a constitutive protein (HIF-1 $\beta$ ) to form a dimer (HIF-1), which translocates into the nucleus upregulating the expression of genes involved in angiogenesis, erythropoiesis, energy metabolism, apoptosis, heat shock and cell proliferation in response to hypoxia (Semenza, 1999; Semenza, 2000a). The role of HIF-1 $\alpha$ as a physiological mediator of the protective effects of ischemic preconditioning has been extensively demonstrated (Bergeron et al., 2000; Grimm et al., 2005; Semenza, 2000b). The observed increases in HIF-1 $\alpha$ nuclear content after repetitive breath-holds suggest that

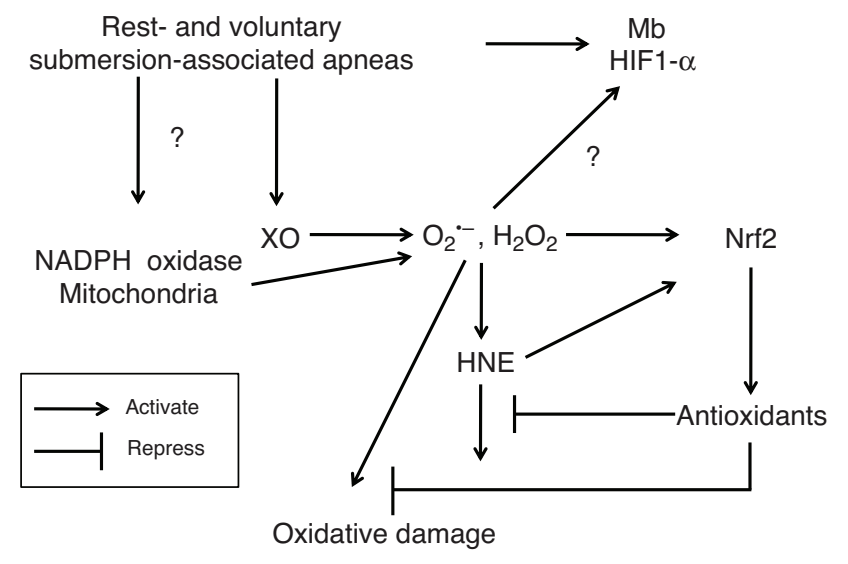

Fig. 6. Schematic representation of the proposed mechanisms leading to the activation of the protective responses against oxidative stress and hypoxia in elephant seal pups exposed to repetitive rest- and voluntary submersion-associated apneas. $\mathrm{H}_{2} \mathrm{O}_{2}$, hydrogen peroxide; $\mathrm{HIF}-1 \alpha$, hypoxia inducible factor $1 \alpha$; HNE, 4-hydroxynonenal; Mb, myoglobin; Nrf2, NF-E2related factor $2 ; \mathrm{O}_{2}{ }^{-}$, superoxide radical; $\mathrm{XO}$, xanthine oxidase.

rest-and voluntary submersion-associated apneas also contribute to the preconditioning of the seal's muscle by activating the HIF-1mediated adaptive response to hypoxia (Johnson et al., 2004; Johnson et al., 2005; Zenteno-Savín et al., 2002). The observed increase in $\mathrm{Mb}$ further supports the latter idea as $\mathrm{Mb}$ is upregulated in response to hypoxia in mammalian tissues and cells (Kanatous and Mammen, 2010), and without physical activity in vertebrates adapted to dive such as penguins (Ponganis et al., 2010) and seals (Noren et al., 2005).

In summary, the results of the present study demonstrate that rather than causing systemic oxidative damage and despite inducing hypoxemia and increasing xanthine, $\mathrm{HX}$ and XO, rest- and voluntary submersion-associated apneas stimulate adaptive responses to hypoxia and oxidative stress in elephant seals by increasing HIF$1 \alpha, \mathrm{Mb}, \mathrm{Nrf2}$, SOD1 and catalase (Fig.6). Thus, experiencing repetitive breath-holds while on land appears to precondition developing elephant seal pups by upregulating their antioxidant system, HIF- $1 \alpha$ and $\mathrm{Mb}$, and thus preparing them to tolerate the repetitive bouts of extended hypoxemia and ischemia/reperfusion/ reoxygenation associated with their ensuing diving lifestyle. Understanding the mechanisms that allow adapted mammals to naturally avoid oxidative damage has the potential to advance therapeutic approaches for oxidative stress-induced pathologies in the long term.

\begin{tabular}{ll} 
8-isoPGF & \multicolumn{1}{c}{ LIST OF ABBRE } \\
$\mathrm{GSH}$ & 8-isoprostanes \\
$\mathrm{H}_{2} \mathrm{O}_{2}$ & hlutathione \\
$\mathrm{HIF}-1 \alpha$ & hydrogen peroxide \\
$\mathrm{HNE}$ & 4-hydroxynonenal \\
$\mathrm{HX}$ & hypoxanthine \\
$\mathrm{Mb}$ & myoglobin \\
$\mathrm{Nrf2}$ & NF-E2-related factor 2 \\
$\mathrm{NT}$ & nitrotyrosine \\
$\mathrm{O}_{2}{ }^{--}$ & superoxide radical \\
$\mathrm{P}_{\mathrm{O}}$ & oxygen partial pressure \\
$\mathrm{RBCs}$ & red blood cells \\
$\mathrm{XDH}$ & xanthine dehydrogenase \\
$\mathrm{XO}$ & xanthine oxidase
\end{tabular}




\section{ACKNOWLEDGEMENTS}

We thank D. Houser, S. Boaz, V. Farnham, J. Jelincic and L. Ranalli for their help with animal handling, J. Viscarra, S. Balayan, R. Rodriguez and J. Minas for assisting with laboratory analyses, and two anonymous reviewers for valuable comments that helped us to improve the this manuscript.

\section{FUNDING}

J.P.V.-M. is supported by fellowships from The University of California Institute for Mexico and The United States (UC MEXUS), Mexico's Consejo Nacional de Ciencia y Tecnología (CONACYT), Mexico's Ministry of Education (SEP) and the University of California Miguel Velez Scholarship Fund. This research was funded by UC MEXUS, CONACYT and the National Institutes of Health (NHLBI R01-

HL09176). Deposited in PMC for release after 6 months.

\section{REFERENCES}

Baines, C. P., Goto, M. and Downey, J. M. (1997). Oxygen radicals released during ischemic preconditioning contribute to cardioprotection in the rabbit myocardium. J. Mol. Cell. Cardiol. 29, 207-216.

Bergeron, M., Gidday, J. M., Yu, A. Y., Semenza, G. L., Ferriero, D. M. and Sharp, F. R. (2000). Role of hypoxia inducible factor 1 in hypoxia induced ischemic tolerance in neonatal rat brain. Ann. Neurol. 48, 285-296.

Blackwell, S. B. and Le Boeuf, B. J. (1993). Developmental aspects of sleep apnoea in northern elephant seals, Mirounga angustirostris. J. Zool. 231, 437-447.

Bloom, D. A. and Jaiswal, A. K. (2003). Phosphorylation of Nrf2 at Ser40 by protein kinase $\mathrm{C}$ in response to antioxidants leads to the release of Nrf2 from INrf2, but is not required for Nrf2 stabilization/accumulation in the nucleus and transcriptional activation of antioxidant response element-mediated $\mathrm{NAD}(\mathrm{P}) \mathrm{H}:$ quinone oxidoreductase-1 gene expression. J. Biol. Chem. 278, 44675-44682.

Burns, J. M., Lestyk, K. C., Folkow, L. P., Hammill, M. O. and Blix, A. S. (2007). Size and distribution of oxygen stores in harp and hooded seals from birth to maturity. J. Comp. Physiol. B 177, 687-700.

Burns, J. M., Skomp, N., Bishop, N., Lestyk, K. and Hammill, M. (2010) Development of aerobic and anaerobic metabolism in cardiac and skeletal muscles from harp and hooded seals. J. Exp. Biol. 213, 740-748.

Castellini, M. A., Milsom, W. K., Berger, R. J., Costa, D. P., Jones, D. R., Castellini, J. M., Rea, L. D., Bharma, S. and Harris, M. (1994). Patterns of respiration and heart rate during wakefulness and sleep in elephant seal pups. $A m$. J. Physiol. Regul. Integr. Comp. Physiol. 266, R863-R869.

Champagne, C. D. (2011). Carbohydrate metabolism while fasting in the northern elephant seal. PhD dissertation, Department of Ecology \& Evolutionary Biology, University of California, Santa Cruz, Santa Cruz, CA, USA.

Corral-Debrinski, M., Stepien, G., Shoffner, J. M., Lott, M. T., Kanter, K. and Wallace, D. C. (1991). Hypoxemia is associated with mitochondrial DNA damage and gene induction. JAMA 266, 1812-1816.

Elsner, R. (1999). Living in water: solutions to physiological problems. In Biology of Marine Mammals (ed. J. E. I. Reynolds and S. A. Rommel), pp. 73-116. Washington, DC: Smithsonian Institution Press.

Elsner, R. and Gooden, B. (1983). Diving and Asphyxia: a Comparative Study of Animals and Man. Cambridge: Cambridge University Press.

Elsner, R., Øyasæter, S., Almaas, R. and Saugstad, O. D. (1998). Diving seals, ischemia-reperfusion and oxygen radicals. Comp. Biochem. Physiol. A Mol. Integr Physiol. 119, 975-980.

Furtado-Filho, O. V., Polcheira, C., Machado, D. P., Mourão, G. and Hermes-Lima, M. (2007). Selected oxidative stress markers in a South American crocodilian species. Comp. Biochem. Physiol. C Toxicol. Pharmacol. 146, 241-254.

Furuichi, T., Liu, W., Shi, H., Miyake, M. and Liu, K. J. (2005). Generation of hydrogen peroxide during brief oxygen glucose deprivation induces preconditioning neuronal protection in primary cultured neurons. J. Neurosci. Res. 79, 816-824.

Gottlieb, R. A., Burleson, K., Kloner, R. A., Babior, B. and Engler, R. (1994) Reperfusion injury induces apoptosis in rabbit cardiomyocytes. J. Clin. Invest. 94, 1621-1628.

Grimm, C., Hermann, D., Bogdanova, A., Hotop, S., Kilic, U., Wenzel, A., Kilic, E. and Gassmann, M. (2005). Neuroprotection by hypoxic preconditioning: HIF-1 and erythropoietin protect from retinal degeneration. Semin. Cell Dev. Biol. 16, 531-538.

Hermes-Lima, M. and Zenteno-Savín, T. (2002). Animal response to drastic changes in oxygen availability and physiological oxidative stress. Comp. Biochem. Physiol. C Toxicol. Pharmacol. 133, 537-556.

Immenschuh, S. and Baumgart-Vogt, E. (2005). Peroxiredoxins, oxidative stress, and cell proliferation. Antioxid. Redox Signal. 7, 768-777.

Itoh, K., Chiba, T., Takahashi, S., Ishii, T., Igarashi, K., Katoh, Y., Oyake, T., Hayashi, N., Satoh, K. and Hatayama, I. (1997). An Nrf2/small Maf heterodimer mediates the induction of phase II detoxifying enzyme genes through antioxidant response elements. Biochem. Biophys. Res. Commun. 236, 313-322.

Ivan, M., Kondo, K., Yang, H., Kim, W., Valiando, J., Ohh, M., Salic, A., Asara, J. M., Lane, W. S. and Kaelin, W. G., Jr (2001). HIF targeted for VHL-mediated destruction by proline hydroxylation: implications for $\mathrm{O}_{2}$ sensing. Science 292, 464468.

Jaiswal, A. K. (2004). Nrf2 signaling in coordinated activation of antioxidant gene expression. Free Radic. Biol. Med. 36, 1199-1207.

Johnson, P., Elsner, R. and Zenteno-Savín, T. (2004). Hypoxia-inducible factor in ringed seal (Phoca hispida) tissues. Free Radic. Res. 38, 847-854

Johnson, P., Elsner, R. and Zenteno-Savín, T. (2005). Hypoxia-inducible factor 1 proteomics and diving adaptations in ringed seal. Free Radic. Biol. Med. 39, 205212.

Kanatous, S. B. and Mammen, P. P. A. (2010). Regulation of myoglobin expression. J. Exp. Biol. 213, 2741-2747.
Kobayashi, A., Kang, M. I., Okawa, H., Ohtsuji, M., Zenke, Y., Chiba, T., Igarashi, K. and Yamamoto, M. (2004). Oxidative stress sensor Keap1 functions as an adaptor for Cul3-based E3 ligase to regulate proteasomal degradation of Nrf2. Mol. Cell. Biol. 24, 7130-7139.

Kobayashi, A., Kang, M. I., Watai, Y., Tong, K. I., Shibata, T., Uchida, K. and Yamamoto, M. (2006). Oxidative and electrophilic stresses activate Nrf2 through inhibition of ubiquitination activity of Keap1. Mol. Cell. Biol. 26, 221-229.

Kooyman, G. L. (1989). Diverse Divers: Physiology and Behavior. Berlin: SpringerVerlag.

Kooyman, G. and Ponganis, P. (1998). The physiological basis of diving to depth: birds and mammals. Annu. Rev. Physiol. 60, 19-32.

Le Boeuf, B. J., Morris, P. A., Blackwell, S. B., Crocker, D. E. and Costa, D. P. (1996). Diving behavior of juvenile northern elephant seals. Can. J. Zool. 74, 1632-

Leonard, M. O., Kieran, N. E., Howell, K., Burne, M. J., Varadarajan, R., Dhakshinamoorthy, S., Porter, A. G., O'Farrelly, C., Rabb, H. and Taylor, C. T. (2006). Reoxygenation-specific activation of the antioxidant transcription factor Nrf2 mediates cytoprotective gene expression in ischemia-reperfusion injury. FASEB J. 20, 2624-2626.

Lestyk, K., Folkow, L., Blix, A., Hammill, M. and Burns, J. (2009). Development of myoglobin concentration and acid buffering capacity in harp (Pagophilus groenlandicus) and hooded (Cystophora cristata) seals from birth to maturity. $J$. Comp. Physiol. B 179, 985-996.

McCord, J. (1985). Oxygen-derived free radicals in postischemic tissue injury. N. Engl. J. Med. 312, 159-163.

Meir, J. U., Champagne, C. D., Costa, D. P., Williams, C. L. and Ponganis, P. J. (2009). Extreme hypoxemic tolerance and blood oxygen depletion in diving elephan seals. Am. J. Physiol. Regul. Integr. Comp. Physiol. 297, R927-R939.

Mounsey, R., Pang, C., Boyd, J. and Forrest, C. (1992). Augmentation of skeletal muscle survival in the latissimus dorsi porcine model using acute ischemic preconditioning. J. Otolaryngol. 21, 315-320.

Murphy, B. J. and Hochachka, P. W. (1981). Free amino acid profiles in blood during diving and recovery in the Antarctic Weddell seal. Can. J. Zool. 59, 455-459.

Murry, C., Jennings, R. and Reimer, K. (1986). Preconditioning with ischemia: a delay of lethal cell injury in ischemic myocardium. Circulation 74, 1124-1136.

Noren, S., Iverson, S. and Boness, D. (2005). Development of the blood and muscle oxygen stores in gray seals (Halichoerus grypus): implications for juvenile diving capacity and the necessity of a terrestrial postweaning fast. Physiol. Biochem. Zool. 78, 482-490.

Ortiz, R. M., Wade, C. E., Costa, D. P. and Ortiz, C. L. (2002). Renal responses to plasma volume expansion and hyperosmolality in fasting seal pups. Am. J. Physiol. Reg. Integr. Comp. Physiol. 282, R805-R817.

Pang, C. Y., Yang, R. Z., Zhong, A., Xu, N., Boyd, B. and Forrest, C. R. (1995). Acute ischaemic preconditioning protects against skeletal muscle infarction in the pig. Cardiovasc. Res. 29, 782-788

Parks, D., Bulkley, G. and Granger, D. (1983). Role of oxygen-derived free radicals in digestive tract diseases. Surgery 94, 415-422.

Ponganis, P., Stockard, T., Levenson, D., Berg, L. and Baranov, E. (2006). Cardiac output and muscle blood flow during rest-associated apneas of elephant seals. Comp. Biochem. Physiol. 144A, 105-111.

Ponganis, P. J., Kreutzer, U., Stockard, T. K., Lin, P. C., Sailasuta, N., Tran, T. K., Hurd, R. and Jue, T. (2008). Blood flow and metabolic regulation in seal muscle during apnea. J. Exp. Biol. 211, 3323-3332.

Ponganis, P. J., Welch, T. J., Welch, L. S. and Stockard, T. K. (2010). Myoglobin production in emperor penguins. J. Exp. Biol. 213, 1901-1906.

Ridgway, S., Harrison, R. and Joyce, P. (1975). Sleep and cardiac rhythm in the gray seal. Science 187, 553-555.

Semenza, G. L. (1999). Regulation of mammalian $\mathrm{O}_{2}$ homeostasis by hypoxiainducible factor 1. Annu. Rev. Cell Dev. Biol. 15, 551-578.

Semenza, G. L. (2000a). HIF-1: mediator of physiological and pathophysiological responses to hypoxia. J. Appl. Physiol. 88, 1474-1480.

Semenza, G. L. (2000b). Surviving ischemia: adaptive responses mediated by hypoxia-inducible factor 1 . J. Clin. Invest. 106, 809-812.

Siow, R., Ishii, T. and Mann, G. (2007). Modulation of antioxidant gene expression by 4-hydroxynonenal: atheroprotective role of the Nrf2/ARE transcription pathway. Redox Rep. 12, 11-15

Stockard, T., Levenson, D., Berg, L., Fransioli, J., Baranov, E. and Ponganis, P. (2007). Blood oxygen depletion during rest-associated apneas of northern elephant seals (Mirounga angustirostris). J. Exp. Biol. 210, 2607-2617.

Tanito, M., Agbaga, M. P. and Anderson, R. E. (2007). Upregulation of thioredoxin system via Nrf2-antioxidant responsive element pathway in adaptive-retinal neuroprotection in vivo and in vitro. Free Radic. Biol. Med. 42, 1838-1850.

Thornton, S. J., Spielman, D. M., Pelc, N. J., Block, W. F., Crocker, D. E., Costa, D. P., LeBoeuf, B. J. and Hochachka, P. W. (2001). Effects of forced diving on the spleen and hepatic sinus in northern elephant seal pups. Proc. Natl. Acad. Sci. USA 98, 9413-9418.

Umemura, K., Itoh, T., Hamada, N., Fujita, Y., Akao, Y., Nozawa, Y., Matsuura, N. linuma, M. and Ito, M. (2008). Preconditioning by sesquiterpene lactone enhances $\mathrm{H}_{2} \mathrm{O}_{2}$-induced Nrf2/ARE activation. Biochem. Biophys. Res. Commun. 368, 948-954.

Valdivia, P. A., Zenteno-Savín, T., Gardner, S. C. and Alonso Aguirre, A. (2007) Basic oxidative stress metabolites in eastern Pacific green turtles (Chelonia mydas agassizii). Comp. Biochem. Physiol. C Toxicol. Pharmacol. 146, 111-117.

Vázquez-Medina, J. P., Zenteno-Savín, T. and Elsner, R. (2006). Antioxidant enzymes in ringed seal tissues: potential protection against dive-associated ischemia/reperfusion. Comp. Biochem. Physiol. C Toxicol. Pharmacol. 142, 198-204.

Vázquez-Medina, J. P., Zenteno-Savín, T. and Elsner, R. (2007). Glutathione protection against dive-associated ischemia/reperfusion in ringed seal tissues. $J$. Exp. Mar. Biol. Ecol. 345, 110-118. 
Vázquez-Medina, J. P., Crocker, D. E., Forman, H. J. and Ortiz, R. M. (2010). Prolonged fasting does not increase oxidative damage or inflammation in postweaned northern elephant seal pups. J. Exp. Biol. 213, 2524-2530.

Vázquez-Medina, J. P., Olguín-Monroy, N. O., Maldonado, P. D., Santamaría, A., Königsberg, M., Elsner, R., Hammilll, M. O., Burns, J. M. and Zenteno-Savín, T. (2011a). Maturarion increases superoxide radical production without increasing oxidative damage in the skeletal muscle of hooded seals (Cystophora cristata). Can J. Zool. 89, 206-212.

Vázquez-Medina, J. P., Soñanez-Organis, J. G., Burns, J. M., Zenteno-Savín, T. and Ortiz, R. M. (2011b). Antioxidant capacity develops with maturation in the deep diving hooded seal. J. Exp. Biol. 214, 2903-2910.

Vázquez-Medina, J. P., Zenteno-Savín, T., Crocker, D. E., Forman, H. J. and Ortiz, R. M. (2011c). Prolonged fasting increases glutathione biosynthesis in postweaned northern elephant seals. J. Exp. Biol. 214, 1294-1299.

Wilhelm Filho, D., Sell, F., Ribeiro, L., Ghislandi, M., Carrasquedo, F., Fraga, C. G., Wallauer, J. P., Simões-Lopes, P. C. and Uhart, M. M. (2002). Comparison between the antioxidant status of terrestrial and diving mammals. Comp. Biochem. Physiol. A Mol. Integr. Physiol. 133, 885-892.
Yuan, H.-J., Zhu, X.-H., Luo, Q., Wu, Y.-N., Kang, Y., Jiao, J.-J., Gao, W.-Z., Liu, Y.-X. and Lou, J.-S. (2010). Noninvasive delayed limb ischemic preconditioning in rats Increases antioxidant activities in cerebral tissue during severe ischemiareperfusion injury. J. Surg. Res. doi:10.1016/j.jss.2010.11.001.

Zenteno-Savín, T., Clayton-Hernandez, E. and Elsner, R. (2002). Diving seals: are they a model for coping with oxidative stress? Comp. Biochem. Physiol. C Toxicol. Pharmacol. 133, 527-536.

Zenteno-Savín, T., St Leger, J. and Ponganis, P. J. (2010). Hypoxemic and ischemic tolerance in emperor penguins. Comp. Biochem. Physiol. C Toxicol. Pharmacol. 152, 18-23.

Zhang, D. D. and Hannink, M. (2003). Distinct cysteine residues in Keap1 are required for Keap1-dependent ubiquitination of Nrf2 and for stabilization of Nrf2 by chemopreventive agents and oxidative stress. Mol. Cell. Biol. 23, 8137-8151.

Zhu, X. H., Yuan, H. J., Wu, Y. N., Kang, Y., Jiao, J. J., Gao, W. Z., Liu, Y. X., Lou, J. S. and Xia, Z. (2011). Non-invasive limb ischemic pre-conditioning reduces oxidative stress and attenuates myocardium ischemia-reperfusion injury in diabetic rats. Free Radic. Res. 45, 201-210. 